\title{
Effect of Nano-clay on Rheological and Extrusion Foaming Process of a Block-Copolymerized Polypropylene
}

\author{
Mingyi $\mathrm{WANG}^{1, \mathrm{a}}$, Qian $\mathrm{BO}^{1, \mathrm{~b}}$ and Nanqiao $\mathrm{ZHOU}^{2, \mathrm{c}}$ \\ ${ }^{1}$ School of Mechanical and Power Engineering, East China University of Science and Technology, \\ Shanghai 200237, China \\ ${ }^{2}$ Key Laboratory of Polymer Processing Engineering, Ministry of Education, National Engineering \\ Research Center of Novel Equipment for Polymer Processing, South China University of Technology, \\ Guangzhou 510640, China \\ awangmingyi1892@126.com, bianbo@ecust.edu.cn, ${ }^{c}$ nqzhou@scut.edu.cn
}

\begin{abstract}
The effects of nano-clay and the corresponding coupling agent maleic anhydride grafted polypropylene (PP-g-MAH) on thermal properties, rheological properties and extrusion foaming process of a block-copolymerized polypropylene (B-PP) were studied. Supercritical $\mathrm{CO}_{2}\left(\mathrm{SC} \mathrm{CO}_{2}\right)$ was used as the foaming agent with a concentration of $5 \mathrm{wt} \%$. Each step of foamed B-PP/ PP-g-MAH/ nano-clay composites processing is addressed, including mixing of the composites, manufacture of the composites, foaming process of the composites and characterization of the cell structure. The results showed that incorporation of nano-clay and PP-g-MAH caused reduced melt strength and complex viscosity of B-PP. However, the heterogeneous nucleation induced by nano-clay and PP-g-MAH improved the maximum foaming expansion ratio and cell-population density of B-PP foam.
\end{abstract}

\section{Introduction}

PP foam is in growing demand due to its application in various fields as a substitute for polystyrene. However, the processing window of PP for foaming is very narrow, which makes its foaming process difficult to control. As a result, it is challenging to obtain PP foam with high expansion ratio and uniform cell morphology. Traditional fillers such as calcium carbonate, talc, mica, silica, alumina and magnesium hydroxide are introduced into the foaming process of PP at relatively high loadings to improve its foaming behavior [1], which comes at the expense of processability and part appearance. To solve this problem, some researchers tried to incorporate nanofillers into foaming formula of PP, which has been proved to be effective [2-4].

\footnotetext{
* Corresponding author:wangmingyi1892@126.com
} 
This study was made in order to further clarify the mechanism of how nano-clay introduction affected the foaming behavior of PP by using $\mathrm{SC} \mathrm{CO}_{2}$ as the foaming agent in an extrusion foaming process.

\section{Experimental}

\subsection{Materials and Sample Preparation}

The polymer matrix used in this study was B-PP (Australian Borealis Company, BA212E) with a melt flow rate (MFR) of $0.3 \mathrm{~g} / 10 \mathrm{~min}$ (ISO $1133,230{ }^{\circ} \mathrm{C} / 2.16 \mathrm{~kg}$ ). Nano-clay (Southern Clay Products, Inc., USA, Cloisite ${ }^{\circledR}$ 20A) and PP-g-MAH (America Eastman chemical company, Epolene G-3003) were used as the nucleating agent and compatibilizer respectively. $\mathrm{SC}-\mathrm{CO}_{2}$ (linde Company, Canada) with purity of $99.5 \%$ was utilized as the foaming agent.

The dry blending of PP, nano-clay, and PP-g-MAH was carried out in a high speed mixer until obtaining a homogeneous mixture. The concentrations of each ingredient in the formula of the composites and the corresponding DSC results are listed in Table 1. The nano-clay concentration changed from 0 to $5 \mathrm{wt} \%$ to check its effect on rheological properties of the PP formula and cell morphology of the PP foams obtained. Extrusion foaming experiments were conducted on a single-screw extruder foaming system (Germany BRABENDER Company, Brabender: 05-25-000) using a filament die of which the die channel length was $1 \mathrm{~mm}$ and the die diameter was $1.2 \mathrm{~mm}$. The melt flow rate from the die was kept at $13 \mathrm{~g} / \mathrm{min}$ in the extrusion foaming process. The $\mathrm{SC} \mathrm{CO}_{2}$ amount injected was set at 5\% (mass fraction).

Table. 1 composition of the b-pp/pp-g-mah/ nano-clay composites and dsc results

\begin{tabular}{|c|c|c|c|c|c|}
\hline Samples & $\begin{array}{c}w \text { (B-PP) } \\
(\%)\end{array}$ & $\begin{array}{c}w \text { (PP-g-MAH) } \\
(\%)\end{array}$ & $\begin{array}{c}w \text { (Nano-clay) } \\
(\%)\end{array}$ & $\begin{array}{c}T_{\mathrm{m}} \\
\left({ }^{\circ} \mathrm{C}\right)\end{array}$ & $\begin{array}{c}T_{\mathrm{c}} \\
\left({ }^{\circ} \mathrm{C}\right)\end{array}$ \\
\hline 1 & 100 & 0 & 0 & 167.7 & 130.1 \\
\hline 2 & 98 & 1.5 & 0.5 & 167.2 & 130.5 \\
\hline 3 & 96 & 3 & 1 & 167.5 & 129.6 \\
\hline 4 & 88 & 9 & 3 & 166.9 & 131.0 \\
\hline 5 & 80 & 15 & 5 & 166.7 & 130.6 \\
\hline
\end{tabular}

\subsection{Foam Characterization}

The density of the foamed samples was determined by the buoyancy method. For details of the method, see reference [5]. SEM was used to characterize cell morphology of the foamed samples. All of the foamed samples were dipped into liquid nitrogen and then quickly fractured in air before scanning. Then the fractured cross section of the samples was sputter-coated with platinum in a sputter coater (Model polar on SC7620, Quorum Technologies Companies, UK). The cell size and cell-population density were determined based on SEM micrographs. The cell diameter was calculated by averaging the sizes of at least 100 cells in the SEM micrographs. For details of the methods used to calculate the cell population density of the foamed samples, see reference [6]. 


\section{Results and Discussion}

\subsection{DSC test results and discussion}

DSC tests for all samples were carried out with a heating rate of $10^{\circ} \mathrm{C} / \mathrm{min}$ over a temperature range from 20 to $200^{\circ} \mathrm{C}$ with nitrogen atmosphere protection. First sample temperature was heated from $20^{\circ} \mathrm{C}$ to $200^{\circ} \mathrm{C}$, holding at $200^{\circ} \mathrm{C}$ for 5 minutes to remove the thermal history, and then cooled to $20^{\circ} \mathrm{C}$ with a $10^{\circ} \mathrm{C} / \mathrm{min}$ cooling rate, finally re-heated to $200^{\circ} \mathrm{C}$ again. Data for cooling and the second heating cycle were recorded first and then $T_{m}$ and $\mathrm{T}_{\mathrm{c}}$ values for B-PP matrix and B-PP/ PP-g-MAH /nano-clay blends were read from the graphs, as listed in Table 1.

As it can be seen from Table 1, the melting point of all the composites were lower than that of the pure B-PP, while the crystallization temperature of the composites was higher than that of pure B-PP except for sample No.3, of which the crystallization temperature was slightly lower than that of the pure B-PP. The changing trend of crystallization temperature of the B-PP/PP-g-MAH/nano-clay composites is similar to that of LH-PP/nano-clay composites studied in our previous research [7], in which the underlying mechanism was clarified. As such, the crystallization temperature is affected by PP-g-MAH and nano-clay content in the composites.

\subsection{Wide-angle X-ray diffraction (WAXD) test results and discussion}

WAXD tests were conducted on an X-ray diffractometer (Germany Bruker Corporation, Model D8 ADVANCE). WAXD patterns for B-PP/PP-g-MAH/nano-clay composites are shown in Fig.1. Layer spacing for the organically modified nano-clay was $\mathrm{d} 0=2.42 \mathrm{~nm}$, and the corresponding diffraction angle $2 \theta$ was $3.648^{\circ}$. After melt intercalation, as nano-clay contents in B-PP/PP-g-MAH/nano-clay composites were $0.5 \mathrm{wt} \%, 1 \mathrm{wt} \%$, $3 \mathrm{wt} \%$ and $5 \mathrm{wt} \%$, the diffraction angles $2 \theta$ corresponding to the first characteristic peak of nano-clay were $4.606^{\circ}, 4.682^{\circ}, 4.682^{\circ}, 4.698^{\circ}$ respectively, which indicates that the diffraction angle shifts to a larger angle, implying that the corresponding layer spacing for nano-clay in $\mathrm{B}-\mathrm{PP} / \mathrm{PP}-\mathrm{g}-\mathrm{MAH} /$ nano-clay composites decreased compared with that of nano-clay before melt intercalation. Again, with the increase of the nano-clay content in the composites, the layer spacing showed a tendency to decrease. This might be caused by the high viscosity of B-PP used for the research, which made the macromolecular chain of B-PP difficult to insert into the nano-clay layers. Moreover, the cation exchange reaction might occur in the blending process, some alkyl ammonium cations were replaced, resulting in decrease of the layer spacing. 


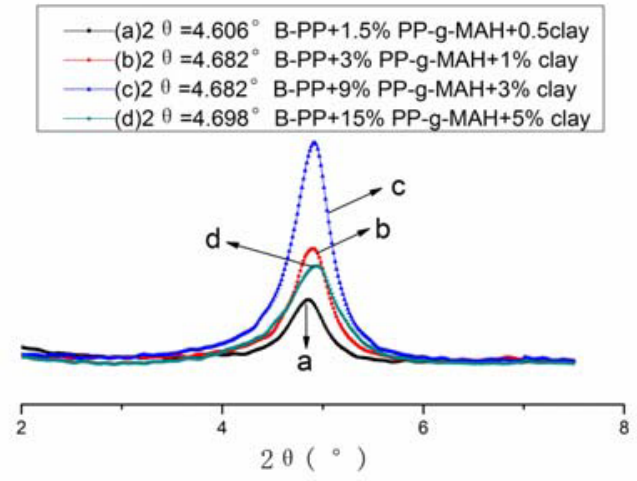

Fig. 1 Wide angle X-ray diffraction patterns for B-PP/PP-g-MAH/Nano-clay composites

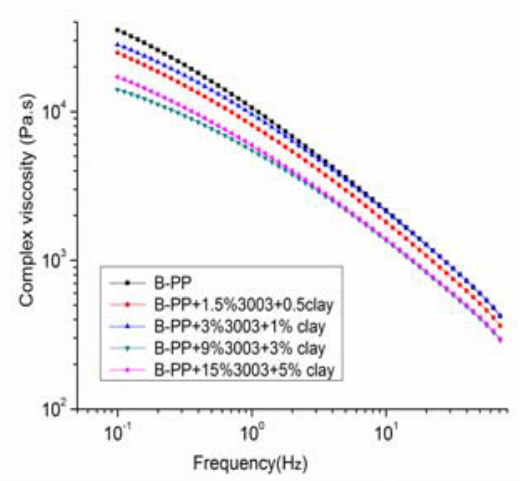

Fig.2 Complex viscosity of B-PP and B-PP/PP-g-MAH/Nano-clay composites

\subsection{Rheological properties test results and discussion}

Table. 2 melt strength values of b-pp/pp-g-mah/nano-clay COMPOSITES

\begin{tabular}{|c|c|c|c|c|}
\hline Samples & $w$ (B-PP & $w$ (PP-g-MAH & $w$ (Nano-clay & Melt strength $(\mathrm{CN})$ \\
\hline 1 & 100 & 0 & 0 & 13.9 \\
\hline 2 & 98 & 1.5 & 0.5 & 12.4 \\
\hline 3 & 96 & 3 & 1 & 11.45 \\
\hline 4 & 88 & 9 & 3 & 6.9 \\
\hline 5 & 80 & 15 & 5 & 8.41 \\
\hline
\end{tabular}

A high pressure capillary rheometer (Italy CEAST Corporation, Model CEAST Rheologic 5000) was used to determine the tensile melt strength of B-PP matrix and the corresponding B-PP/PP-g-MAH/nano-clay composites, with a drawing acceleration of $2.5 \mathrm{~mm} / \mathrm{s}^{2}$. The tensile melt strength of B-PP/PP-g-MAH/nano-clay composites at $190^{\circ} \mathrm{C}$ was listed in Table 2. As can be seen from Table 2, compared with that of pure B-PP, the tensile melt strength of B-PP/PP-g-MAH/nano-clay composites decreased to a certain extent and with the increase of nano-clay and PP-g-MAH content in the composites, the tensile melt strength of the composites decreased initially and then increased. This is because that the addition of nano-clay can increase the melt strength of the composites, while the addition of PP-g-MAH with high MFR can reduce the viscosity and the corresponding melt strength of the composites. With the increase of nano-clay and PP-g-MAH content in the composites, nano-clay or PP-g-MAH may become the dominant factor influencing the melt strength, causing the melt strength increase or decrease.

Dynamic shearing rheological properties tests for B-PP and B-PP/PP-g-MAH/nano-clay composites were conducted on a strain-controlled ARES rheometer, with $25 \mathrm{~mm}$ parallel-plate geometry and a 1-mm sample gap. Dynamic shear measurements with frequencies from 0.1 to $70 \mathrm{~Hz}$ were taken at a temperature of $210^{\circ} \mathrm{C}$ with nitrogen atmosphere protection. Strain was maintained at $10 \%$ to ensure linear viscoelasticity. Fig. 2 shows the complex viscosity of B-PP and B-PP/PP-g-MAH/nano-clay composites, which indicates that with the increase of nano-clay and PP-g-MAH content, the complex viscosity 
of the composites also decreased initially and then increased, showing a similar changing trend with tensile melt strength shown in Table 2.

\subsection{Effect of die temperature and formulation on expansion ratio of foam products obtained from B-PP/PP-g-MAH/Nano-clay composites}

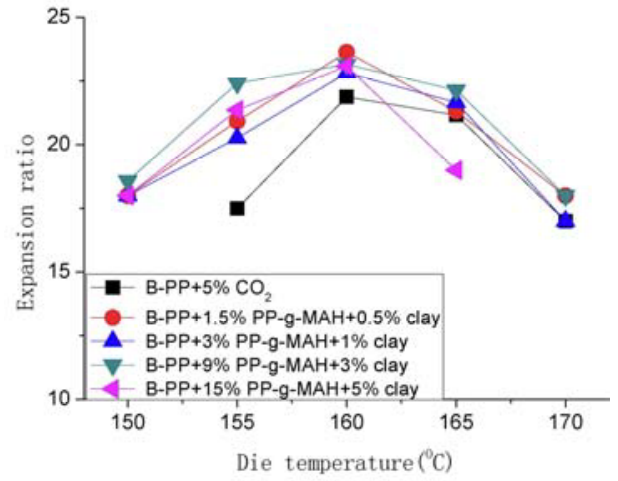

Fig. 3 Effect of die temperature and blend ratio on expansion ratio of foam products obtained from B-PP/PP-g-MAH/Nano-clay composites

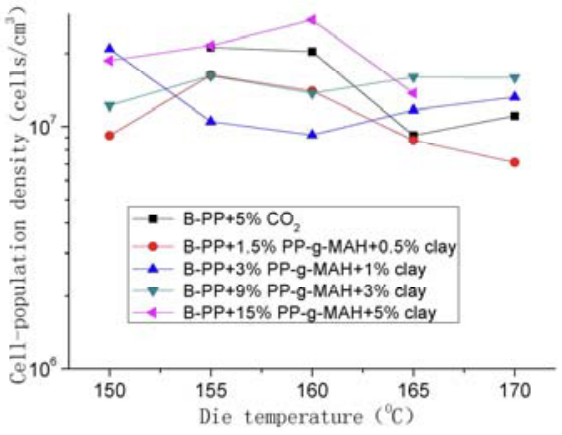

Fig.4 Effect of die temperature and blend ratio on cell-population density of foam products obtained from B-PP/ PP-g-MAH/ Nano-clay blends

As seen in Fig.3, when $5 \mathrm{wt} \% \mathrm{SC} \mathrm{CO}_{2}$ was injected as the foaming agent, the addition of nano-clay and PP-g-MAH increased the maximum expansion ratio of the B-PP foam, but the improvement was not that obvious. This is based on the fact that on the one hand, the introduction of nano-clay and PP-g-MAH provided more nucleation sites and made more gas used for bubble nucleation and growth; on the other hand, the incorporation of PP-g-MAH decreased melt strength, resulting in gas loss and reduced expansion ratio. The final expansion ratio obtained is the result for competition between the above two mechanisms.

\subsection{Effect of die temperature and formulation on cell-population density of foam products obtained from B-PP/PP-g-MAH/Nano-clay composites}

Fig.4 shows the effects of die temperature and formulation on cell-population density of the foamed B-PP samples. Overall speaking, as $\mathrm{SC} \mathrm{CO}_{2}$ content was $5 \mathrm{wt} \%$, the introduction of nano-clay and PP-g-MAH did not increase the cell-population density of the foam products from B-PP/PP-g-MAH/nano-clay composites as compared with that from pure $\mathrm{B}-\mathrm{PP}$ matrix. This is because that on the one hand, the introduction of nano-clay and PP-g-MAH triggered the heterogeneous nucleation, providing a large number of nucleation sites, which would raise the cell-population density; on the other hand, the addition of nano-clay and PP-g-MAH decreased the complex viscosity and melt strength of the composites as compared with pure B-PP matrix, resulting in loss of gas used for bubble nucleation. The final cell-population density is the result for competition between the above two mechanisms.

As shown in Fig.4, as nano-clay content in the foaming formula is $0.5 \mathrm{wt} \%$, $1 \mathrm{wt} \%$ and $3 \mathrm{wt} \%$, the cell-population density of the foam for B-PP/PP-g-MAH/nano-clay composites decreased to some extent when compared that from pure B-PP, which implied that the reduced melt strength caused by incorporation of nano-clay and PP-g-MAH was the main 
factor determining the cell-population density; when nano-clay content was further increased to $5 \mathrm{wt} \%$ in the formula, the cell-population density of the foam obtained from $\mathrm{B}-\mathrm{PP} / \mathrm{PP}-\mathrm{g}-\mathrm{MAH} /$ nano-clay composites was higher than that of pure B-PP, indicating that the heterogeneous nucleation induced by introduction of nano-clay and PP-g-MAH was the main mechanism determining the cell-population density.

\section{Conclusions}

Through the study of effects of nano-clay and PP-g-MAH introduction on thermal properties, rheological properties of B-PP and on expansion ratio, as well as cell-population density of B-PP foam, the following conclusions were drawn:

1. The melting point for B-PP/PP-g-MAH/nano-clay composites were lower than that of the pure B-PP, while the crystallization temperature of the composites was higher than that of pure B-PP except for sample No.3, of which the crystallization temperature was slightly lower than that of the pure B-PP.

2. The corresponding layer spacing for nano-clay in B-PP/PP-g-MAH/nano-clay composites decreased as compared with that of nano-clay before melt intercalation, and with the increase of nano-clay content in the composites, the layer spacing showed a tendency to decrease.

3. Compared with that of pure B-PP, the tensile melt strength of B-PP/PP-g-MAH/nano-clay composites decreased to a certain extent and with the increase of nano-clay and PP-g-MAH content in the composites, the tensile melt strength of the composites decreased initially and then increased. As such, the complex viscosity of the composites also decreased initially and then increased with the increase of nano-clay and PP-g-MAH content, showing a similar changing trend with tensile melt strength

4. The addition of nano-clay and PP-g-MAH increased the maximum expansion ratio of the B-PP foam, but the improvement was not that obvious.

5. Due to two competitive mechanisms caused by incorporation of nano-clay and $\mathrm{PP}-\mathrm{g}-\mathrm{MAH}$, as $\mathrm{SC} \mathrm{CO}_{2}$ content was $5 \mathrm{wt} \%$, the introduction of nano-clay and PP-g-MAH did not increase the cell-population density of the foam products from $\mathrm{B}-\mathrm{PP} / \mathrm{PP}-\mathrm{g}-\mathrm{MAH} /$ nano-clay composites as compared with that from pure B-PP matrix.

\section{Acknowledgements}

This work was supported by the National Natural Science Foundation of China (Grant No. 21206152) and Beijing Natural Science Foundation (Grant No. 3132007).

\section{References}

1. S.H. Lee, Y. Zhang, M. Kontopoulou, C.B. Park, A. Wong, W. Zhai, Optimization of Dispersion of Nanosilica Particles in a PP Matrix and Their Effect on Foaming, Intern. Polymer Processing. 26(2011) 388-398.

2. W.T. Zhai, C.B. Park, M. Kontopoulou, Nanosilica Addition Dramatically Improves the Cell Morphology and Expansion Ratio of Polypropylene Heterophasic Copolymer Foams Blown in Continuous Extrusion, Ind. Eng. Chem. Res. 50(2011) 7282-7289.

3. W.T. Zhai, C.B. Park, Effect of Nanoclay Addition on the Foaming Behavior of Linear Polypropylene-Based Soft Thermoplastic Polyolefin Foam Blown in Continuous Extrusion, Polym. Eng. Sci. 51(2011) 2387-2397.

4. M. Nofar, K. Majithiya, T. Kuboki, C.B. Park, The foamability of low-melt-strength linear polypropylene with nanoclay and coupling agent, J Cell Plast. 48(2012) 271-287. 
5. M.Y. Wang, J. Ma, R. Chu, C.B. Park, N.Q. Zhou, Effect of the Introduction of Polydimethylsiloxane on the Foaming Behavior of Block-Copolymerized Polypropylene, J Appl Polym Sci. 123(2012) 2726-2732.

6. D.F. Baldwin, C.B. Park, N.P. Suh, A Microcellular Processing Study of Poly(Ethylene Terephthalate) in the Amorphous and Semicrystalline States. Part I: Microcell Nucleation, Polym. Eng. Sci. 36(1996) 1437-1445.

7. M.Y. Wang, L.Q. Ji, J. Ma, N.Q. Zhou, Extrusion Foaming of Linear Polypropylene Homopolymer/Nano-clay Blends, Polymer Materials Science \& Engineering. 27(2011) 114-117. 